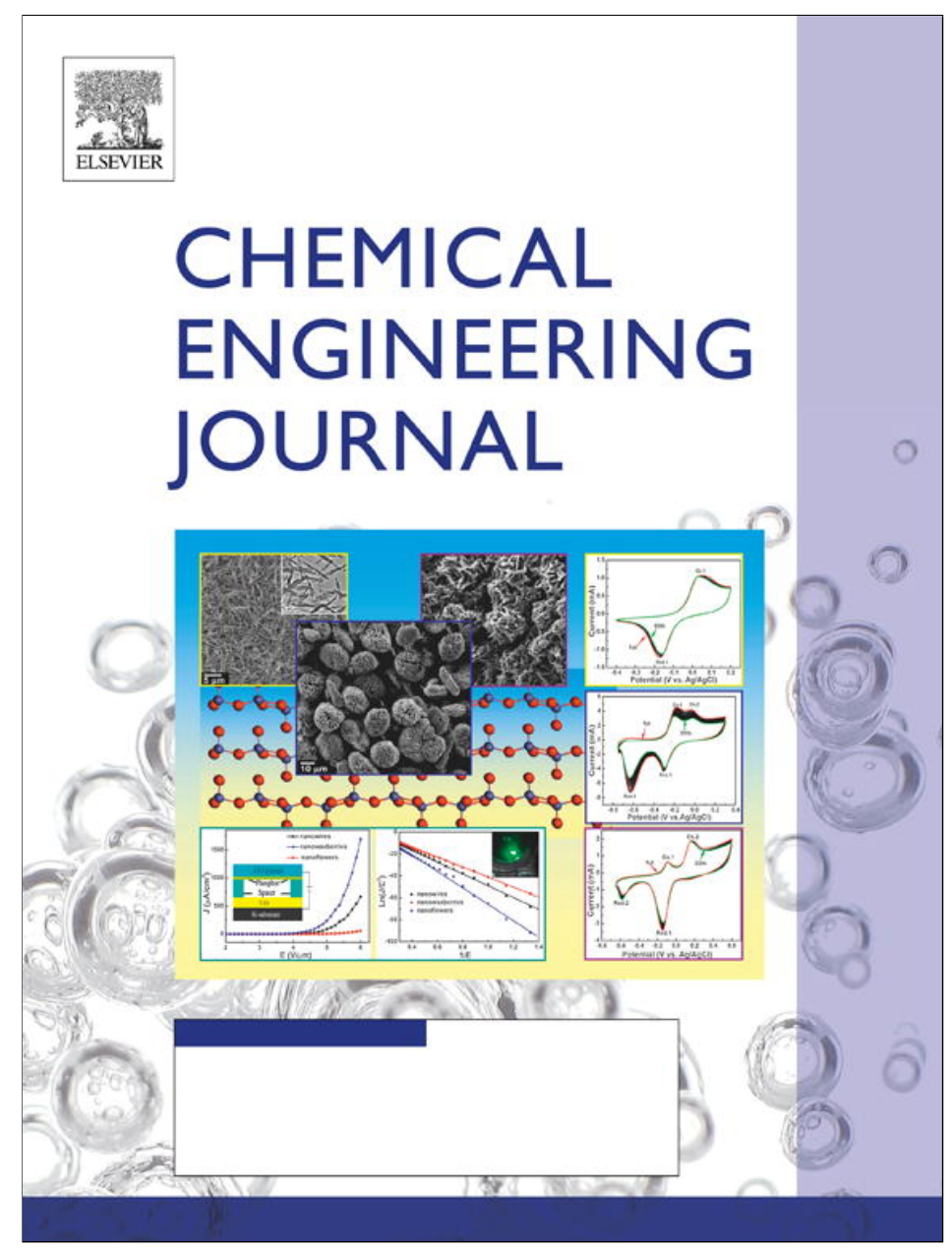

(This is a sample cover image for this issue. The actual cover is not yet available at this time.)

This article appeared in a journal published by Elsevier. The attached copy is furnished to the author for internal non-commercial research and education use, including for instruction at the authors institution and sharing with colleagues.

Other uses, including reproduction and distribution, or selling or licensing copies, or posting to personal, institutional or third party websites are prohibited.

In most cases authors are permitted to post their version of the article (e.g. in Word or Tex form) to their personal website or institutional repository. Authors requiring further information regarding Elsevier's archiving and manuscript policies are encouraged to visit: 


\title{
Incorporation of selectivity factor in modeling binary component adsorption isotherms for heavy metals-biomass system
}

\author{
Felycia Edi Soetaredjo*, Alfin Kurniawan, Ong Lu Ki, Suryadi Ismadji \\ Department of Chemical Engineering, Widya Mandala Surabaya Catholic University, Kalijudan 37, Surabaya 60114, Indonesia
}

\section{H I G H L I G H T S}

- Utilisation of rice straw as a cheap and effective sorbent for the removal of $\mathrm{Cu}$ and $\mathrm{Pb}$ ions.

- Incorporation of selectivity factor of solute for the modification of extended-Langmuir model.

- Representation of binary adsorption data and the model fittings in 3D plots.

- Application of biosorption study using real effluent from a wastewater treatment plant.

- Regeneration study of biosorbent for industrial practice.

\section{A R T I C L E I N F O}

\section{Article history:}

Received 21 October 2012

Received in revised form 19 December 2012

Accepted 26 December 2012

Available online 11 January 2013

\section{Keywords:}

Biosorption

Rice straw

Extended Langmuir

Selectivity

Binary components

\begin{abstract}
A B S T R A C T
The single and binary biosorption of copper and lead ions from aqueous solution using a low cost agrobased resource (i.e. rice straw) has been demonstrated in this work. The biosorption experiments were performed in a static mode. Experimental parameters affecting the sorption process namely biosorbent dose, $\mathrm{pH}$, and temperature were studied. Two empirical adsorption models (i.e. Langmuir and Freundlich) were used for the evaluation of biosorption equilibrium data in single system. Both models were able to correlate experimental data satisfactorily. The adsorptivity of solute $\left(K_{\mathrm{L}}\right)$ and maximum sorption capacity of the solid $\left(q_{\mathrm{m}}\right)$ were increased at higher temperatures. For binary metal system, we modified the adsorption parameters of extended-Langmuir model (i.e. $K_{\mathrm{L}-b i n}$ and $q_{\mathrm{m} \text {-bin }}$ ) by introducing selectivity factor of the solute $(S)$. It was found that the modified extended-Langmuir model with incorporation of solute's selectivity factor gave good correlation results against binary adsorption data with reasonable fitted parameter values. The feasibility and biosorption performance of rice straw in sequestering copper and lead ions was also tested using real effluent along with its regeneration possibility.
\end{abstract}

(c) 2013 Elsevier B.V. All rights reserved.

\section{Introduction}

Heavy metals are a type of pollutants that are generated from various industrial activities such as metal plating, mining, metallurgical, leather tanning, batteries, alloy, and electronic goods manufacturing. Despite of their importance for economic growth in most countries including Indonesia, the discharged wastewater containing considerable amounts of heavy metal ions is of a major concern to the environment. The contamination of heavy metals in the surface waters, groundwater, and soil causes deterioration of soil and water qualities and gives adverse impacts on the growth of terrestrial and aquatic organisms [1-3]. Moreover, the distribution and accumulation of this substance in food chains often pose serious threats to public health $[4,5]$. Copper $(\mathrm{Cu})$ and lead $(\mathrm{Pb})$ are two kinds of heavy metals that are widely used since ancient times

\footnotetext{
* Corresponding author. Tel.: +62 31389 1264; fax: +62 313891267.

E-mail address: felyciae@yahoo.com (F.E. Soetaredjo).
}

and their negative effects on human health have been assessed [6]. The Indonesian government has set the regulation for maximum levels of $\mathrm{Pb}$ and $\mathrm{Cu}$ ions in industrial effluents discharged into inland surface waters (Table 1 ). To obey this regulation, the industries have to treat their effluents properly before discharge into environment.

Many conventional methods are available for the treatment of metal-bearing effluent such as electrochemical [7], biological treatment [8], membrane separation [9], coagulation [10], chemical precipitation [11], reverse osmosis [12], solvent extraction [13], and ion exchange [14]. However, the application of such methods is often limited, particularly in handling effluents containing trace amounts of heavy metal ions (1-100 mg/l) due to incomplete metal removal, energy-intensive, economically expensive, and generation of secondary waste products (e.g. toxic sludge) that require proper disposal techniques without creating any problem to the environment. To this end, adsorption has proven as a cost-effective and high efficiency method that produced high quality effluents with 
Table 1

The maximum levels of lead and copper heavy metals in industrial effluents discharged into inland surface waters.

\begin{tabular}{llll}
\hline Category & Target of uses & Lead $^{\mathrm{a}}$ & Copper $^{\mathrm{a}}$ \\
\hline A & Drinking water (direct-consumed) & 0.05 & 1 \\
B & Bottled drinking water & 0.1 & 1 \\
C & Fishery and livestock & 0.03 & 0.02 \\
D & Agricultural, urban business, industry, and & 1 & 0.2 \\
& hydro power-plant & & \\
\hline
\end{tabular}

${ }^{\mathrm{a}}$ In the unit concentration of $\mathrm{mg} / \mathrm{l}$.

minimum environmental impacts [15]. One of the key successes of adsorption process in removing heavy metal ions from water and wastewater lies in the selection of the adsorbing material (or adsorbent). To ensure the effectiveness and economic feasibility of the process, the adsorbents should have the following criteria: (1) high loading capacity; (2) cheap; (3) abundant availability; and (4) regenerable. Out of criteria above, commercial activated carbons may satisfy the first and the fourth criteria while the second and the third become the main limitations for large-scale use of this adsorbent in water and wastewater treatment processes.

Recently, the lignocellulosic solid wastes generated from agricultural and forestry sectors have been highlighted as potential adsorbents for the removal of heavy metal ions from water and wastewater [16]. Among the aforesaid criteria, the lignocellulosic-based adsorbents may satisfy three or all criteria although their adsorption capacities are lower than activated carbons. Rice straw that produced from harvesting process of paddy can be utilised as a low cost and effective biosorbent for such purpose. This crop waste mainly composed of natural polymer materials such as lignin, cellulose, and hemicelluloses, which are known to be the binding sites of heavy metal ions [16]. The availability of rice straw in Indonesia is huge with total production reached eighty millions tons in 2011. Of this amount, 30-40\% have been used as cattle feeds, $7-15 \%$ have been used for handicrafts making, and the rest (about 50\%) ends up as a waste [17]. A common method to reduce excess quantities of rice straw is by incineration, which not only causes an air pollution but also waste of natural resources. Therefore, an advantageous waste management process for unused rice straw is by utilising them as a biosorbent for purifying metalbearing effluents.

This work deals with the evaluation of biosorption performance of rice straw for the removal of copper and lead ions in single and binary component systems. Although biosorption studies of heavy metal ions in single system using pristine or chemically-modified rice straw have been well reported in the last few years [18-21], however, the adsorption equilibria aspect of multicomponent system and its modeling still needs to be explored. Several adsorption models such as extended-Langmuir, extended-Freundlich, and ideal adsorption solution theory (IAST) models (e.g. Fast-IAS theory, real adsorption solution theory) have been developed to describe multicomponent adsorption equilibria. Despite of their reasonable success, the applications of IAST and its modified forms are restricted due to their complex algorithm and the use of an elaborate computer programming for solving the model. In other hand, extended-Langmuir is the most extensively used model featuring its simple approach in describing multicomponent adsorption equilibria. The correlation of adsorption equilibrium data by extended-Langmuir model is mostly performed through a comparison between experimental and theoretical amounts of $q_{\mathrm{e}}$ (i.e. the equilibrium concentration of adsorptive in the adsorbed state). However, this procedure lacks of theoretical sounds and often fails to describe experimental data satisfactorily because it does not address the competitive adsorption in the system. To respond this problem, we propose modification on the adsorption parameters of extended-Langmuir model that incorporates selectivity factor of the solute $(S)$. To the best of our knowledge, there is no report in the literature regarding the incorporation of solute's selectivity factor for the modification of extended Langmuir parameters (i.e. $q_{\mathrm{m} \text {-bin }}$ and $\left.K_{\mathrm{L}-b i n}\right)$ and its model fitting against binary adsorption equilibrium data of heavy metals-biomass system. The regeneration and metal recovery studies of spent biosorbent were also conducted in order to evaluate the feasibility and reliability of rice straw for practical applications.

\section{Experimental sections}

\subsection{Chemicals}

Analytical grade $\mathrm{CuSO}_{4} \cdot 5 \mathrm{H}_{2} \mathrm{O}$ and $\mathrm{Pb}\left(\mathrm{NO}_{3}\right)_{2}$ as metal ion sources were purchased from Sigma-Aldrich, Singapore. Deionized water was used throughout all experiments in this work.

\subsection{Preparation of biosorbent}

Rice straw in this work was collected from a rice field located near the border of Lumajang city, East Java, Indonesia. After the collection, the straw was cut into a size of $1 \times 1 \mathrm{~cm}$ and boiled with deionized water for $2 \mathrm{~h}$ to remove color materials. The decolorized straw was then washed with deionized water three times and dried in an oven at $80^{\circ} \mathrm{C}$ for $24 \mathrm{~h}$. The biomass was then crushed with an IKA-Labortechnick grinder and sieved to obtain particle size of $150-180 \mu \mathrm{m}$. Finally, the product was kept in airtight plastic bag for further experimental use.

\subsection{Characterizations of biosorbent}

The surface morphology of rice straw was visualized in a JEOL JSM-6300F field emission scanning electron microscopy. Prior to scanning, the sample was coated with a conductive film of platinum using an Eiko IB-5 sputter-coater operated at $6 \mathrm{~mA}$ for $4 \mathrm{~min}$ in argon atmosphere. The surface scanning was performed at an electron acceleration voltage of $20 \mathrm{kV}$, four aperture, eight spot size, and $9 \mathrm{~mm}$ working distance.

The pore structure of rice straw was analyzed by a Quadrasorb SI sorption analyzer using nitrogen as the adsorbate at $77.15 \mathrm{~K}$ and relative pressure $\left(p / p^{0}\right)$ ranging from 0.005 to 0.995 . The specific surface area of biosorbent was obtained by means of the BET method applied at $p / p^{0}$ range of $0.06-0.3$.

The surface functional groups of biosorbent were identified by infrared spectroscopy technique, using a Shimadzu FTIR-8400S spectrophotometer. The analysis was conducted based on the $\mathrm{KBr}$ disk method with 200 cumulative scans in a scanning range of $4000-500 \mathrm{~cm}^{-1}$.

The $\mathrm{pH}$ of point of zero charge $\left(\mathrm{pH}_{\mathrm{pzc}}\right)$ of rice straw was determined by pH-drift method [22] and found to be 3.2 .

Han and Rowell method [23] was applied for quantification of the percentage composition of lignin, cellulose, and hemicellulose in rice straw (wt\%, dry matter) and it was found to be $17.4 \%, 38.2 \%$, and $20.6 \%$, respectively.

The composition of inorganic matters (minerals) in rice straw such as $\mathrm{Na}, \mathrm{K}, \mathrm{Mg}$, and Ca was analyzed by a MiniPal QC energy dispersive X-ray fluorescence spectrometer (PANalytical) and the results are given as follows: $\mathrm{Na}=0.09 \% ; \mathrm{K}=1.87 \% ; \mathrm{Mg}=0.23 \%$; and $\mathrm{Ca}=0.52 \%$.

\subsection{Static biosorption experiments}

The stock solutions of copper and lead ions at initial concentration of $100 \mathrm{mg} / \mathrm{l}(1.57 \mathrm{mmol} / \mathrm{l}-\mathrm{Cu}(\mathrm{II})$ and $0.48 \mathrm{mmol} / \mathrm{l}-\mathrm{Pb}(\mathrm{II}))$ 
were prepared by dissolving a known amount of $\mathrm{CuSO}_{4} \cdot 5 \mathrm{H}_{2} \mathrm{O}$ and $\mathrm{Pb}\left(\mathrm{NO}_{3}\right)_{2}$ into $500 \mathrm{ml}$ deionized water. The single and binary biosorption isotherm experiments were performed by adding a prescribed amount of biosorbent ranging from $1 \mathrm{~g}$ to $20 \mathrm{~g}$ into a series of stoppered conical flasks containing $100 \mathrm{ml}$ metal solution. The flasks were then placed in a Memmert thermostatic shaker water-bath and shaken at desired temperature $\left(30^{\circ} \mathrm{C}, 40^{\circ} \mathrm{C}\right.$, $50{ }^{\circ} \mathrm{C}$, and $60^{\circ} \mathrm{C}$ ) with a shaking speed of $100 \mathrm{rpm}$. Preliminary experiments show that biosorption equilibrium time was reached within 3-4 h. Subsequently, the flasks were removed from the bath and the mixture was filtered pass through a Whatman filter paper to remove solid particles. The residual concentration of metal ions in the filtrate was analyzed using a Shimadzu AA-6200 atomic absorption flame emission spectrophotometer. The measurements were performed at a wavelength corresponding to the maximum absorbance of each metal ion species, i.e. $324.4 \mathrm{~nm}$ for copper and $216.7 \mathrm{~nm}$ for lead.

The effect of $\mathrm{pH}$ on the biosorption of $\mathrm{Cu}$ (II) and $\mathrm{Pb}$ (II) ions in single and binary component systems was investigated at $\mathrm{pH}$ range of 1-6 since the formation of metal hydroxide precipitates, i.e. $\mathrm{Cu}(\mathrm{OH})_{2}$ and $\mathrm{Pb}(\mathrm{OH})_{2}$, occurs at $\mathrm{pH}$ higher than 6 . The $\mathrm{pH}$ of metal solutions was adjusted by the addition of $0.1 \mathrm{M} \mathrm{HCl}$ solution as per required.

\subsection{Calculations}

The amounts of $\mathrm{Cu}(\mathrm{II})$ and $\mathrm{Pb}(\mathrm{II})$ ions adsorbed onto rice straw in single solute system were calculated by following equation:

$q_{\mathrm{e}}=\frac{\left(C_{0}-C_{\mathrm{e}}\right)}{m} \times V$

where $C_{0}$ and $C_{\mathrm{e}}$ are the initial and equilibrium concentrations of metal ions in the liquid phase $(\mathrm{mmol} / \mathrm{l}), V$ is the volume of metal solution (1), $q_{\mathrm{e}}$ is the amount of metal ions adsorbed per unit of biosorbent mass $(\mathrm{mmol} / \mathrm{g})$, and $m$ is the mass of biosorbent $(\mathrm{g})$. The equilibrium concentration of metal $i$ species $\left(C_{\mathrm{e}, i}\right)$ in binary mixture can be calculated by the same manner using following mass balance equation:

$q_{\mathrm{e}, i}=\frac{\left(C_{0, i}-C_{\mathrm{e}, i}\right)}{m} \times V$

where $q_{\mathrm{e}, i}$ is the equilibrium amount of solute $i$ in the adsorbed phase (mmol/g), $C_{0, i}$ and $C_{\mathrm{e}, i}$ are the initial and equilibrium concentrations of solute $i$ in the liquid phase ( $\mathrm{mmol} / \mathrm{l})$, respectively. For reproducibility test, all experiments were repeated three times with averages used as the results.

\section{Results and discussion}

\subsection{Characterizations of biosorbent}

The surface morphology of rice straw, as visualized by SEM at magnifications of $5000 \times$ and $10000 \times$ is depicted in Fig. 1 . It was found that rice straw belongs to a nonporous solid material with respect to its surface smoothness. This surface characteristic was also revealed from the $\mathrm{N}_{2}$ adsorption-desorption isotherm results (figure not shown). The specific surface area of rice straw $\left(S_{\mathrm{BET}}\right)$ is fairly low $\left(40.7 \mathrm{~m}^{2} / \mathrm{g}\right)$ with total pore volume $\left(V_{\mathrm{T}}\right)$ of $0.11 \mathrm{~cm}^{3} / \mathrm{g}$ at STP. Low $\mathrm{N}_{2}$ sorption capacity of rice straw may be ascribed to the low porosity in the solid matrices.

The presence of natural heteropolymer materials like lignin, cellulose, and hemicelluloses in biosorbent was evidenced from FTIR results (spectra not shown). Several strong absorption bands were noted at wavenumbers of $3618 \mathrm{~cm}^{-1}, 2941 \mathrm{~cm}^{-1}$, and $1127 \mathrm{~cm}^{-1}$. These bands correspond to the $\mathrm{O}-\mathrm{H}$ stretch of phenol groups, $\mathrm{C}-\mathrm{H}$ stretch of alkanes groups, and $\mathrm{C}-\mathrm{O}$ stretch of carboxylic acids, alkoxy groups, or fiber carbonaceous that presented in the lignocellulosic structure. The presence of aromatic $\mathrm{C}-\mathrm{C}$ stretch and aliphatic $C=C$ stretch was observed at wavenumbers of $1596 \mathrm{~cm}^{-1}$ and $1671 \mathrm{~cm}^{-1}$, respectively. Two moderate bands at wavenumbers of $1082 \mathrm{~cm}^{-1}$ and $464 \mathrm{~cm}^{-1}$ reflected the vibration of silicaeous groups, associated with $\mathrm{Si}-\mathrm{O}$ stretch and $\mathrm{Si}-\mathrm{O}$ bend, respectively.

After biosorption, several absorption bands namely $\mathrm{O}-\mathrm{H}$ stretch and $\mathrm{C}-\mathrm{O}$ stretch were altered. The reduced peak energy and the shifting of $\mathrm{O}-\mathrm{H}$ stretch from $3618 \mathrm{~cm}^{-1}$ to $3583 \mathrm{~cm}^{-1}$ were due to the deformation of this band after metal ions binding. Another shifting was observed in $\mathrm{C}-\mathrm{O}$ stretch from $1127 \mathrm{~cm}^{-1}$ to $1079 \mathrm{~cm}^{-1}$ and $\mathrm{Si}-\mathrm{O}$ stretch from $1082 \mathrm{~cm}^{-1}$ to $1051 \mathrm{~cm}^{-1}$, indicating the involvement of these functional groups in the metal sorption process. Moreover, two new peaks at around $1400 \mathrm{~cm}^{-1}$ and $1600 \mathrm{~cm}^{-1}$ were observed, associated with the vibration bands of metal-carboxylate functional groups (COO-M) where $\mathrm{M}$ refers to lead or copper ions. This result implies that the binding of metal ions onto rice straw takes place via complexation or chelating mechanism with hydroxylate and carboxylate surface groups as the main adsorption sites and silicaeous groups in lesser extent through unidentate or bidentate coordination types.

In order to investigate whether ion exchange plays a major role in the metal sorption process, the concentrations of inorganic matters such as $\mathrm{Na}, \mathrm{K}, \mathrm{Ca}$, and $\mathrm{Mg}$ in the solid before and after biosorption were analyzed. It was found that the concentrations of these minerals in pristine and metal-loaded biosorbents were slightly different and can be regarded essentially unchanged. This denotes that the binding of metal ions onto rice straw predominantly occurred by surface complexation or chelation mechanism (as evidenced from FTIR results) and ion exchange in lesser extent. For the latter mechanism, it was found to be predominant in the biosorption using algae or seaweed biomass, as verified in several studies [24-26].

\subsection{Effects of $p H$}

The adsorption behavior of heavy metal ions and other contaminants such as dyes, natural organic matters, etc. in aqueous phase strongly depends on $\mathrm{pH}$ and may be different for each solute-sorbent interaction. The pH-dependence of metal biosorption has been verified by many researchers, which are relevant to the ionic state of surface functionalities on the adsorbent and the metal chemistry in the solution. The effect of $\mathrm{pH}$ on the removal of $\mathrm{Cu}$ (II) and $\mathrm{Pb}(\mathrm{II})$ ions by rice straw from single and binary mixture was investigated in a $\mathrm{pH}$ range of 1-6 and the results are shown in Fig. 2. It can be seen that the percentage removal of both metal ions steeply increased with increasing $\mathrm{pH}$ from 3 to 5 , continued by a slight increase with increasing $\mathrm{pH}$ from 5 to 6 . For binary component system, the highest percentage removal of metal ions was observed at $\mathrm{pH}$ about 6 . Hence, $\mathrm{pH} 6$ was selected as the optimum point and used throughout single and binary biosorption experiments in this work.

At $\mathrm{pH}$ value below the $\mathrm{pH}_{\mathrm{pzc}}$ of biosorbent (i.e. $\mathrm{pH} 1-3$ ), the surface functional groups on the solid (primarily carboxylic acids) were protonated by hydronium ions $\left(\mathrm{H}^{+}\right)$hence the overall surface charge on the solid was positive. The protonation of carboxylic acid surface groups by $\mathrm{H}^{+}$ions occurred as follows:

$$
\mathrm{R}-\mathrm{COOH}+\mathrm{H}^{+} \rightarrow \mathrm{R}-\mathrm{COOH}_{2}^{+}
$$

As the result, an electrostatic repulsion force was generated between metal ions and positively charged solid surface that retards metal binding process. In addition, high concentrations of $\mathrm{H}^{+}$ions in the solution also competed with metal species for the adsorption sites on the solid surface. 

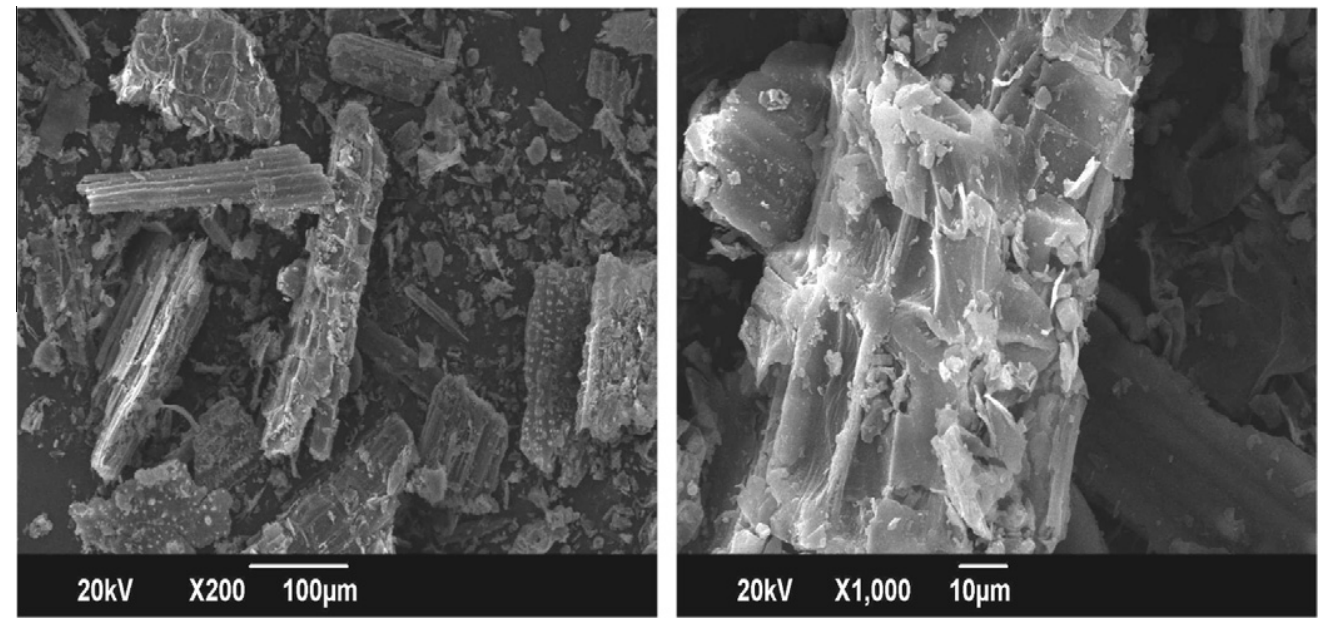

Fig. 1. SEM micrographs of rice straw at magnifications of $200 \times$ and $1000 \times$.

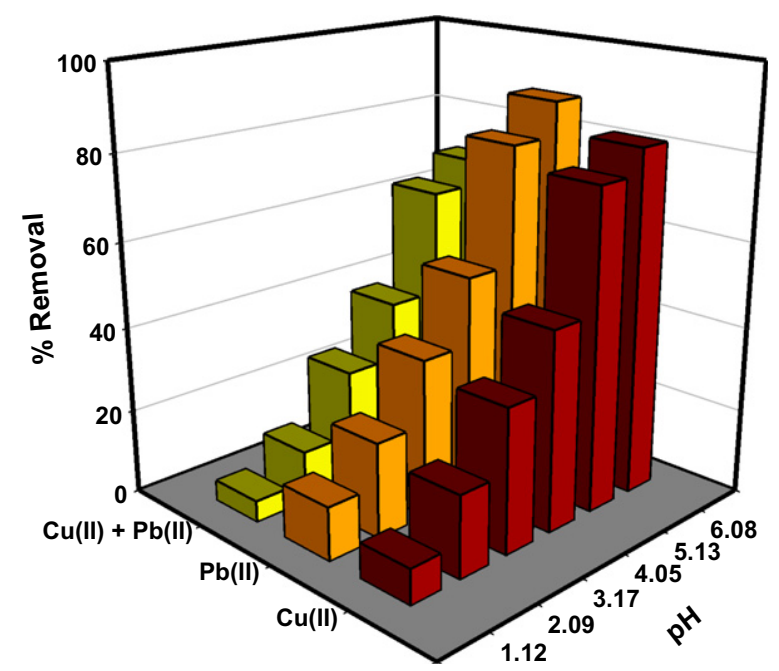

Fig. 2. Effect of $\mathrm{pH}$ on the removal of $\mathrm{Cu}^{2+}$ and $\mathrm{Pb}^{2+}$ ions from single and binary solutions.

Increasing $\mathrm{pH}$ of the solution above the $\mathrm{pH}_{\mathrm{pzc}}$ of the solid facilitated the sorption process. This is due to the increased negative charge density on the biosorbent surface because of the dissociation of carboxylic acids to carboxylate anions $\left(\mathrm{R}-\mathrm{COO}^{-}\right)$that took place in a pH range between 3.5 and 5.5, which is the range of acid dissociation value ( $\mathrm{pKa}$ ) of carboxylic acids. Hence, an electrostatic attraction force between the deprotonated solid surface and metal ions occurred and facilitated biosorption process. Furthermore, the occurring competitions between metal ions and $\mathrm{H}+$ for the adsorption sites become weaker with increasing $\mathrm{pH}$ of the solution.

\subsection{Biosorption mechanism of $\mathrm{Cu}(\mathrm{II})$ and $\mathrm{Pb}(\mathrm{II})$ ions onto rice straw}

When dealing with the investigation of adsorption mechanism of adsorbate onto the adsorbent surface, the information regarding the shift of functional groups and the presence of new absorption bands can be used as valuable hints. The main constituents of rice straw namely lignin, cellulose, and hemicelluloses are known to be associated, in part, hydroxyl, carboxyl, and phenol functional groups, which are responsible in providing the adsorption sites for metal ions. These oxygen-containing surface groups are $\mathrm{pH}-$ dependent hence the change in $\mathrm{pH}$ would affect the chemical state and charge density of these functionalities. As explained above, when $\mathrm{pH}$ of the solution was above $\mathrm{pH}_{\mathrm{pzc}}$ of the biosorbent, the surface functional groups of biosorbent were deprotonated and negatively charged ligands were formed. Conversely, the surface groups were protonated by hydronium ions when $\mathrm{pH}$ of the solution was below the $\mathrm{pH}_{\mathrm{pzc}}$ of biosorbent, bearing a positive charge on the solid surface which tends to repulse the cationic-type adsorbates.

The first stage of metal biosorption process was the deprotonation of hydroxyl group in carboxyl and phenol functionalities to form negatively charged hydroxylate and carboxylate sites. The next stage was the release of hydration waters from the hydrated metal ions, leaving the non-solvated cationic species in the solution. The last stage was the uptake of non-solvated metal ions through electrostatic attractive forces between these species and negatively charged carboxyl or phenol oxygen atoms. Among the three stages above, the role of $\mathrm{pH}$ was remarkably important in the first stage because it governed the protonation and deprotonation of surface functionalities and the chemistry of metal species. Meanwhile, the sorption mechanism of copper and lead ions onto rice straw surface in binary mixture was essentially similar to that of single component system, except for the occurring competition between each metal species for the adsorption sites.

\subsection{Modeling of adsorption isotherms}

\subsubsection{Single component system}

The information of the equilibrium relationship between the concentration of adsorbate in the liquid phase and adsorbed phase, also known as the adsorption isotherms is of great importance in the adsorption studies, not only for the design purpose, but also in understanding the adsorption equilibria, kinetics, and thermodynamics of single and multicomponent systems. In this regard, two adsorption models namely Langmuir and Freundlich were used to evaluate adsorption equilibrium data of single component system. Langmuir developed an adsorption theory based on the kinetic principle and proposed the monolayer surface adsorption on the ideal solid with definite localised sites that energetically identical [27]. This model further assumes that the adsorbate molecules can only accommodate one localised site without lateral interactions between the adsorbed molecules, even on the adjacent sites. Graphically, Langmuir isotherm is characterized by a plateau curve, which means that no further adsorption can be occurred when equilibrium established. Originally, this empirical model was developed for describing adsorption phenomena in the gas 
phase but it had been extensively used for the correlation of adsorption equilibrium data of various solute-sorbent interactions in the liquid phase [19-21]. The mathematical form of Langmuir isotherm model is given as follows:

$q_{\mathrm{e}}=q_{\mathrm{m}} \frac{K_{\mathrm{L}} \cdot C_{\mathrm{e}}}{1+K_{\mathrm{L}} \cdot C_{\mathrm{e}}}$

where $q_{\mathrm{m}}$ is the maximum adsorptive capacity of the solid (mmol/ $\mathrm{g}$ ), corresponds to the monolayer surface coverage (i.e. the adsorbate layer is one molecule in thickness) and $K_{\mathrm{L}}$ is Langmuir constants of adsorption affinity $(1 / \mathrm{mmol})$. As the value of $C_{\mathrm{e}}$ becomes lower, the term of $K_{\mathrm{L}} \cdot C_{\mathrm{e}}$ is much less than unity and Langmuir isotherm will obey Henry's law behavior. In contrast, when the value of $C_{e}$ getting higher, the saturation point of adsorption will be reached and the concentration of solute on the solid surface will be equal to the maximum sorption capacity. The essential characteristic of Langmuir isotherm on the adsorption nature can be assessed by following equation [28]:

$R_{\mathrm{L}}=\frac{1}{1+K_{\mathrm{L}} \cdot C_{0}}$

where $R_{\mathrm{L}}$ is a dimensionless equilibrium parameter or the separation factor and $C_{0}$ is the initial concentration of metal solution (mmol/l). The value of $R_{\mathrm{L}}$ denotes the adsorption nature to be unfavorable $\left(R_{\mathrm{L}}>1\right)$, favorable $\left(0<R_{\mathrm{L}}<1\right)$, irreversible $\left(R_{\mathrm{L}}=0\right)$, or linear $\left(R_{\mathrm{L}}=1\right)$.

The second adsorption model used was Freundlich. Freundlich [29] proposed an empirical adsorption model on the solid with non-ideal nature, i.e. the adsorption energy and affinity are varied over the surface. This isotherm is not restricted to only monolayer surface adsorption and can be used adequately for describing the adsorption behavior in heterogeneous systems, particularly for the adsorption of organic matters by activated carbons, molecular sieves, and other solids with a complex structure. Freundlich isotherm model has a mathematical form as follows:

$q_{\mathrm{e}}=K_{\mathrm{F}} \times C_{\mathrm{e}}^{1 / n}$

Here, $K_{\mathrm{F}}$ and $n$ are Freundlich constants of adsorption affinity $\left((\mathrm{mmol} / \mathrm{g})(\mathrm{mmol} / \mathrm{L})^{-n}\right)$ and degree of heterogeneity of the system, respectively. Higher value of $n$ indicates a greater degree of heterogeneity and the system increasingly deviated from linear isotherm. When $n$ value was higher than about 10 , the system approached a rectangular or non-reversible isotherm [30]. Generally, Freundlich isotherm agreed well in a narrow range of adsorption data, typically at moderate concentrations because this isotherm does not have Henry's law limit at low concentration and saturation limit at high-end concentration. Moreover, this isotherm assumes that an infinite amount of adsorption can be occurred (i.e. the concentration of solute on the solid surface continues to rise with increasing concentration in the liquid phase), which means that no saturation limit at high-end concentration.

The plots of biosorption equilibrium data of $\mathrm{Cu}(\mathrm{II})$ and $\mathrm{Pb}(\mathrm{II})$ ions at various temperatures are displayed in Fig. 3. The parameter values of the models were determined by nonlinear regression fitting using SigmaPlot software (Version 12.3, Systat Software Inc.) and the results are given in Table 2. In Fig. 3, it can be seen that both Langmuir and Freundlich models can correlate experimental data satisfactorily with coefficient of determination $\left(R^{2}\right)$ approaching unity. However, a deeper analysis of the model, associated with justification of the physical meaning of the model parameters should be conducted. The affinity constants of solute toward the solid surface (i.e. $K_{\mathrm{L}}$ and $K_{\mathrm{F}}$ ) were increased at higher temperatures, indicating that high temperature facilitated the sorption process. This is due to greater kinetic energy in the system that caused the molecules to move around faster and increase the adsorptivity
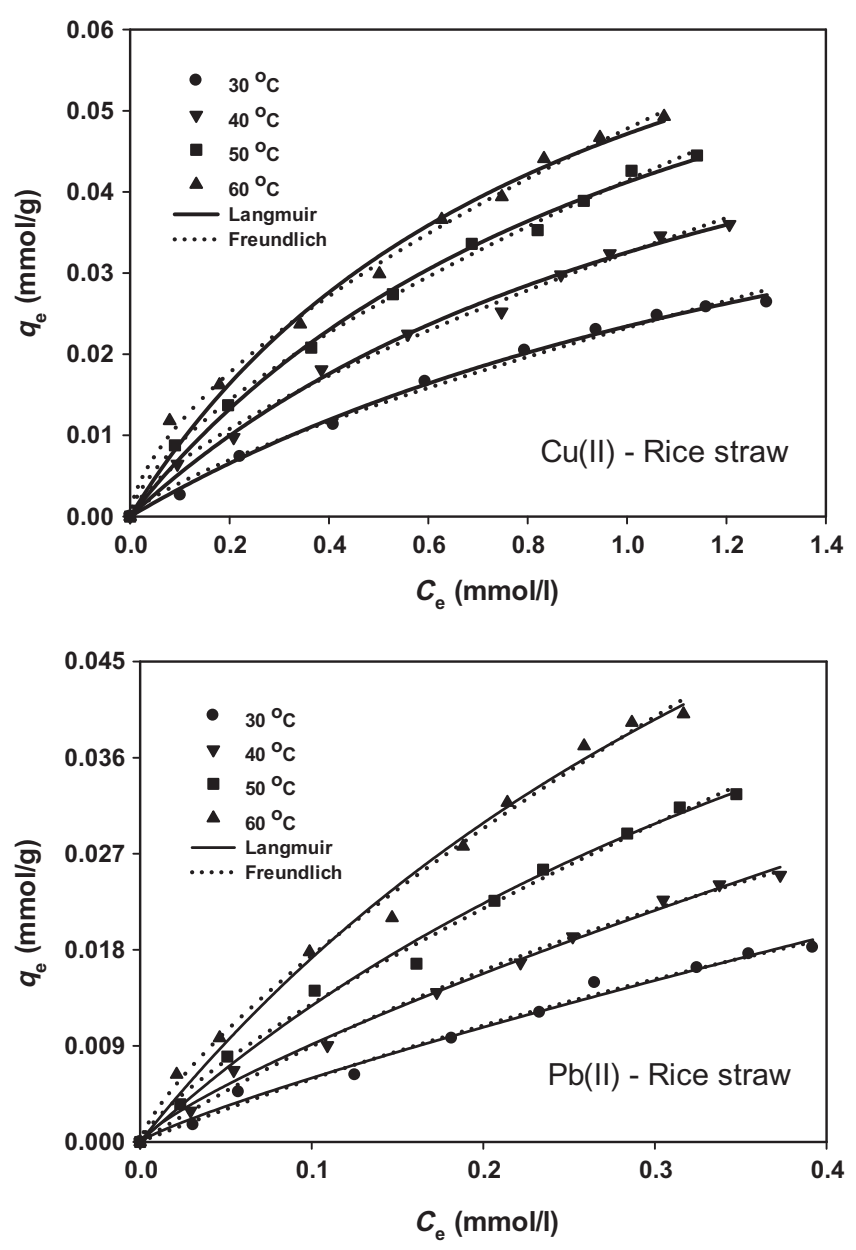

Fig. 3. Biosorption isotherm plots of $\mathrm{Cu}^{2+}$ and $\mathrm{Pb}^{2+}$ ions at various temperatures.

of solute. Because the Pauling electronegativity of $\mathrm{Pb}^{2+}$ ion is greater than $\mathrm{Cu}^{2+}$ ion (i.e. 2.33 vs. 1.95) and the ionic size of the former is larger than the latter (i.e. $1.19 \AA$ As. $0.73 \AA$ ) [31], a stronger electrostatic interaction between $\mathrm{Pb}^{2+}$ ion and deprotonated carboxyl and hydroxyl surface functionalities was expected hence $\mathrm{Pb}^{2+}$ ion was preferentially adsorbed than $\mathrm{Cu}^{2+}$ ion. Similar behavior was observed for the maximum uptake capacity of the solid at higher temperatures. The $q_{\mathrm{m}}$ values for $\mathrm{Cu}^{2+}$ and $\mathrm{Pb}^{2+}$ ions at $60{ }^{\circ} \mathrm{C}$ were $0.0891 \mathrm{mmol} / \mathrm{g}(5.66 \mathrm{mg} / \mathrm{g})$ and $0.1127 \mathrm{mmol} / \mathrm{g}(23.35 \mathrm{mg} / \mathrm{g})$, respectively. As comparison, the maximum sorption capacities of several biomass-based sorbents for sequestering copper and lead ions from water and wastewater are listed in Table 3 [32-39]. With respect to $R_{\mathrm{L}}$ values, all systems exhibit favorable biosorption nature. Moreover, the magnitude of all isotherm parameters obtained in this work agreed well with those reported previously in the literature for metal ion-biomass sorption systems [19-21,32,40].

As explained above, the movement of the molecules becomes faster at higher temperatures that increased the randomness degree of the system. This behavior was consistently described by Freundlich model, associated with the increasing value of $n$ with temperature. Interestingly, it was also noted that the heterogeneity degree of $\mathrm{Pb}$ (II)-rice straw is lower than $\mathrm{Cu}(\mathrm{II})$-rice straw at all temperatures. Through all analyses above, it can be concluded that the Langmuir and Freundich models were able to correlate biosorption equilibrium data satisfactorily from both graphical and parameter justification point of view along with reasonable values of the fitted parameters. 
Table 2

The fitted Langmuir and Freundlich adsorption parameters for $\mathrm{Cu}(\mathrm{II})$-rice straw and $\mathrm{Pb}(\mathrm{II})$-rice straw at various temperatures.

\begin{tabular}{|c|c|c|c|c|c|c|c|c|}
\hline \multirow[t]{2}{*}{ Ion } & \multirow[t]{2}{*}{$T\left({ }^{\circ} \mathrm{C}\right)$} & \multicolumn{3}{|l|}{ Langmuir } & \multicolumn{4}{|c|}{ Freundlich } \\
\hline & & $q_{\mathrm{m}}(\mathrm{mmol} / \mathrm{g})$ & $K_{\mathrm{L}}(\mathrm{l} / \mathrm{mmol})$ & $R^{2}$ & $R_{\mathrm{L}}$ & $K_{\mathrm{F}}(\mathrm{mmol} / \mathrm{g})(\mathrm{mmol} / \mathrm{l})^{-n}$ & $n$ & $R^{2}$ \\
\hline \multirow[t]{4}{*}{$\mathrm{Cu}^{2+}$} & 30 & 0.0659 & 0.5515 & 0.99 & 0.53 & 0.0232 & 1.33 & 0.99 \\
\hline & 40 & 0.0753 & 0.7618 & 0.99 & 0.46 & 0.0325 & 1.46 & 0.99 \\
\hline & 50 & 0.0873 & 0.8945 & 0.99 & 0.42 & 0.0414 & 1.52 & 0.99 \\
\hline & 60 & 0.0891 & 1.1244 & 0.98 & 0.36 & 0.0478 & 1.62 & 0.99 \\
\hline \multirow[t]{4}{*}{$\mathrm{Pb}^{2+}$} & 30 & 0.0740 & 0.8646 & 0.98 & 0.71 & 0.0417 & 1.18 & 0.98 \\
\hline & 40 & 0.0777 & 1.3014 & 0.99 & 0.62 & 0.0560 & 1.27 & 0.99 \\
\hline & 50 & 0.0899 & 1.6526 & 0.99 & 0.56 & 0.0746 & 1.31 & 0.99 \\
\hline & 60 & 0.1127 & 1.8046 & 0.99 & 0.54 & 0.0985 & 1.33 & 0.99 \\
\hline
\end{tabular}

\subsubsection{Binary component system}

In the present work, the biosorption equilibrium data of $\mathrm{Cu}(\mathrm{II})$ and $\mathrm{Pb}$ (II) ions from binary solution were evaluated by selectivity extended-Langmuir model. Before moving further on the proposed model, it is necessary to discuss first the classical extended-Langmuir model that has a mathematical form as follows [30]:

$q_{\mathrm{e}, i}=q_{\mathrm{m}, i} \frac{K_{\mathrm{L}, i} \cdot C_{\mathrm{e}, i}}{1+\sum_{j=1}^{n} K_{\mathrm{L}, i} \cdot C_{\mathrm{e}, i}}$

For binary component system, Eq. (7) becomes:

$q_{\mathrm{e}, 1}=q_{\mathrm{m}, 1} \frac{K_{\mathrm{L}, 1} \cdot C_{\mathrm{e}, 1}}{1+K_{\mathrm{L}, 1} \cdot C_{\mathrm{e}, 1}+K_{\mathrm{L}, 2} \cdot C_{\mathrm{e}, 2}}$

$q_{\mathrm{e}, 2}=q_{\mathrm{m}, 2} \frac{K_{\mathrm{L}, 2} \cdot C_{\mathrm{e}, 2}}{1+K_{\mathrm{L}, 1} \cdot C_{\mathrm{e}, 1}+K_{\mathrm{L}, 2} \cdot C_{\mathrm{e}, 2}}$

where $q_{\mathrm{m}, 1}, q_{\mathrm{m}, 2}, K_{\mathrm{L}, 1}$ and $K_{\mathrm{L}, 2}$ are the Langmuir adsorption parameters for single component system. In most cases, the evaluation of binary adsorption data by extended-Langmuir model was conducted by comparing experimental and theoretical amounts of $q_{\mathrm{e}}$ where the latter was calculated from Eqs. (8) and (9) by introducing the adsorption parameters for single system. Although this procedure can give satisfactory fitting results visually, however, it is lack of theoretical sounds since the adsorption behavior in single and binary systems are completely different. This can be explained by considering that the adsorptivity of solute and maximum surface coverage on the solid in single system are derived from pure component adsorption equilibria without any sorption interference from other solutes. Meanwhile, adsorption in binary component system involves the competition between adsorbate species for the active functional groups on the adsorbent surface. Such phenomenon leads to the surface coverage on the solid by each adsorbate at certain fractional loadings. Hence, the adsorption parameters for single system can no longer be used to describe binary adsorption data. For binary adsorption system, the aforesaid behaviors should be included in the correlation of experimental data. To address this point, we propose modification on the parameters of extended-Langmuir model (i.e. $q_{\mathrm{m} \text {-bin }}$ and $K_{\mathrm{L}-\text { bin }}$ ) that incorporates selectivity factor of the solute to describe the competitive adsorption in the system. The proposed $q_{\mathrm{m}}$ and $K_{\mathrm{L}}$ parameters of extended-Langmuir model for binary adsorption system are as follows:

$q_{m-\text { bin }}=q_{\mathrm{m}, 1-\sin }\left(C_{0,1} \cdot S_{21} / C_{0,1} \cdot S_{21}+C_{0,2} \cdot S_{12}\right)$

$K_{\mathrm{L}, 1-\text { bin }}=K_{\mathrm{L}, 1-\sin } \cdot \exp \left(-S_{21}\right)$

$K_{\mathrm{L}, 2-\text { bin }}=K_{\mathrm{L}, 2-\sin } \cdot \exp \left(-S_{12}\right)$

where $S$ is a dimensionless constant called selectivity factor or the ratio of affinity of each solute towards the solid surface and $C_{0, i}$ is the initial concentration of solute $i$ in the mixture $(\mathrm{mmol} / \mathrm{l})$. The symbol $S_{12}$ denotes the affinity of solute $1\left(b_{1}\right)$ relative to the affinity of solute $2\left(b_{2}\right)$ towards the solid surface and vice versa. Here, $\mathrm{Cu}$ and $\mathrm{Pb}$ ions were designated as solute 1 and solute 2 , respectively. The exponential term was purposely used in order to describe the Langmuirian plots of adsorption isotherms $\left(C_{\mathrm{e}}\right.$ vs. $\left.q_{\mathrm{e}}\right)$ in which the concentration of adsorbate on the solid surface rose exponentially with declining concentration in the liquid phase and tend to be constant when equilibrium is getting closer to be reached. The mathematical relationship between $K_{\mathrm{L}}$ and $S$ can be explained by considering the competitive adsorption between solute 1 and solute 2 in the system. Accordingly, the adsorptivity of each solute towards the solid surface in binary adsorption system should be weaker than that in single system. This behavior also applies to the maximum sorption capacity of the solid which is the sum of maximum sorption capacity of each solute multiplied by the mole fraction of solute adsorbed. By introducing the proposed mathematical forms of $q_{\mathrm{m} \text {-bin }}$ and $K_{\mathrm{L}-\text { bin }}$ (Eqs. (10)-(12)) into Eq. (7), the selectivity extended-Langmuir model for binary adsorption system was obtained:

$$
\begin{aligned}
& q_{\mathrm{e}, 1}=\frac{\left(q_{\mathrm{m}, 1-\sin }\left(C_{0,1} \cdot\left(b_{2} / b_{1}\right) / C_{0,1} \cdot\left(b_{2} / b_{1}\right)+C_{0,2} \cdot\left(b_{1} / b_{2}\right)\right)+q_{\mathrm{m}, 2-\sin }\left(C_{0,2} \cdot\left(b_{1} / b_{2}\right) / C_{0,1} \cdot\left(b_{2} / b_{1}\right)+C_{0,2} \cdot\left(b_{1} / b_{2}\right)\right)\right) K_{\mathrm{L}, 1-\sin } \exp \left(-b_{2} / b_{1}\right) C_{e, 1}}{1+K_{\mathrm{L}, 1-\sin } \exp \left(-b_{2} / b_{1}\right) C_{\mathrm{e}, 1}+K_{\mathrm{L}, 2-\sin } \exp \left(-b_{1} / b_{2}\right) C_{\mathrm{e}, 2}} \\
& q_{\mathrm{e}, 2}=\frac{\left(q_{\mathrm{m}, 1-\sin }\left(C_{0,1} \cdot\left(b_{2} / b_{1}\right) / C_{0,1} \cdot\left(b_{2} / b_{1}\right)+C_{0,2} \cdot\left(b_{1} / b_{2}\right)\right)+q_{\mathrm{m}, 2-\sin }\left(C_{0,2} \cdot\left(b_{1} / b_{2}\right) / C_{0,1} \cdot\left(b_{2} / b_{1}\right)+C_{0,2} \cdot\left(b_{1} / b_{2}\right)\right)\right) K_{\mathrm{L}, 2-\sin } \exp \left(-b_{1} / b_{2}\right) C_{\mathrm{e}, 2}}{1+K_{L, 1-\sin } \exp \left(-b_{2} / b_{1}\right) C_{\mathrm{e}, 1}+K_{\mathrm{L}, 2-\sin } \exp \left(-b_{1} / b_{2}\right) C_{\mathrm{e}, 2}}
\end{aligned}
$$


Table 3

The maximum uptake capacity of several biomass-based sorbents for $\mathrm{Cu}^{2+}$ and $\mathrm{Pb}^{2+}$ ions.

\begin{tabular}{lllllll}
\hline \multirow{2}{*}{ Biomass } & \multicolumn{2}{l}{ Conditions } & & \multicolumn{2}{l}{$q_{\mathrm{m}}(\mathrm{mg} / \mathrm{g})$} & Reference \\
\cline { 2 - 3 } & $\mathrm{pH}$ & $T\left({ }^{\circ} \mathrm{C}\right)$ & & $\mathrm{Cu}^{2+}$ & $\mathrm{Pb}^{2+}$ & \\
\hline Rice straw & 6 & 60 & & 5.66 & 23.35 & This study \\
Barley straw & 6 & 30 & & 4.64 & 23.2 & {$[32]$} \\
Galaxaura oblongata & 5 & 25 & & - & 88.6 & {$[33]$} \\
Ulva lactuca & 5 & 20 & & - & 34.7 & {$[34]$} \\
Banana peel & 5.5 & 30 & - & 7.97 & {$[35]$} \\
Crab shell & 3 & 25 & & 38.62 & & {$[36]$} \\
& 5.5 & & & 19.83 & & \\
Pine Cone Shell & 5 & 25 & & 6.81 & - & {$[37]$} \\
Tea fungal & 4 & 25 & & 4.64 & - & {$[38]$} \\
Garden grass & na & Ambient & 58.34 & - & {$[39]$} \\
\hline
\end{tabular}

a na $=$ Not available.

In the case of single component system, i.e. $C_{0,2}=0$ in Eq. (13) and $C_{0,1}=0$ in Eq. (14), both equations will reduce to single Langmuir isotherm. To test the validity of the proposed model, the fitting results between original and selectivity extended-Langmuir models against experimental data were compared as shown in
Fig. 4-I-III. In these figures, the circle and triangle symbols represented the concentrations of copper and lead ions in binary solution, respectively. For binary adsorption system, the plot of the isotherm model should fit both experimental data points because the concentrations of both solutes in the liquid phase are in dynamic balance with those in the adsorbed state at equilibrium.

Fig. 4-I shows the fitting result between experimental (solid symbols) and theoretical amounts of $q_{\mathrm{e}}$ (wire-mesh plots). As clearly seen, this procedure fails to give good correlation result, revealing the invalid use of Langmuir adsorption parameters of single system for the evaluation of binary adsorption equilibrium data. To give more evidence on this, the evaluation of experimental data by original extended-Langmuir model by nonlinear regression fitting is depicted in Fig. 4-II. It was found that the fitted parameter values $\left(K_{\mathrm{L}, 1}, K_{\mathrm{L}, 2}, q_{\mathrm{m}, 1}\right.$, and $\left.q_{\mathrm{m}, 2}\right)$ obtained for binary adsorption system deviate away than those in single system. In other hand, the proposed selectivity extended-Langmuir model with two fitted parameters (i.e. $b_{1}$ and $b_{2}$ ) satisfactorily representing experimental data in this work (Fig. 4-III).

The fitting of selectivity extended-Langmuir model against adsorption equilibrium data of copper and lead ions from binary solution at various temperatures is displayed in Fig. 5 . It can be
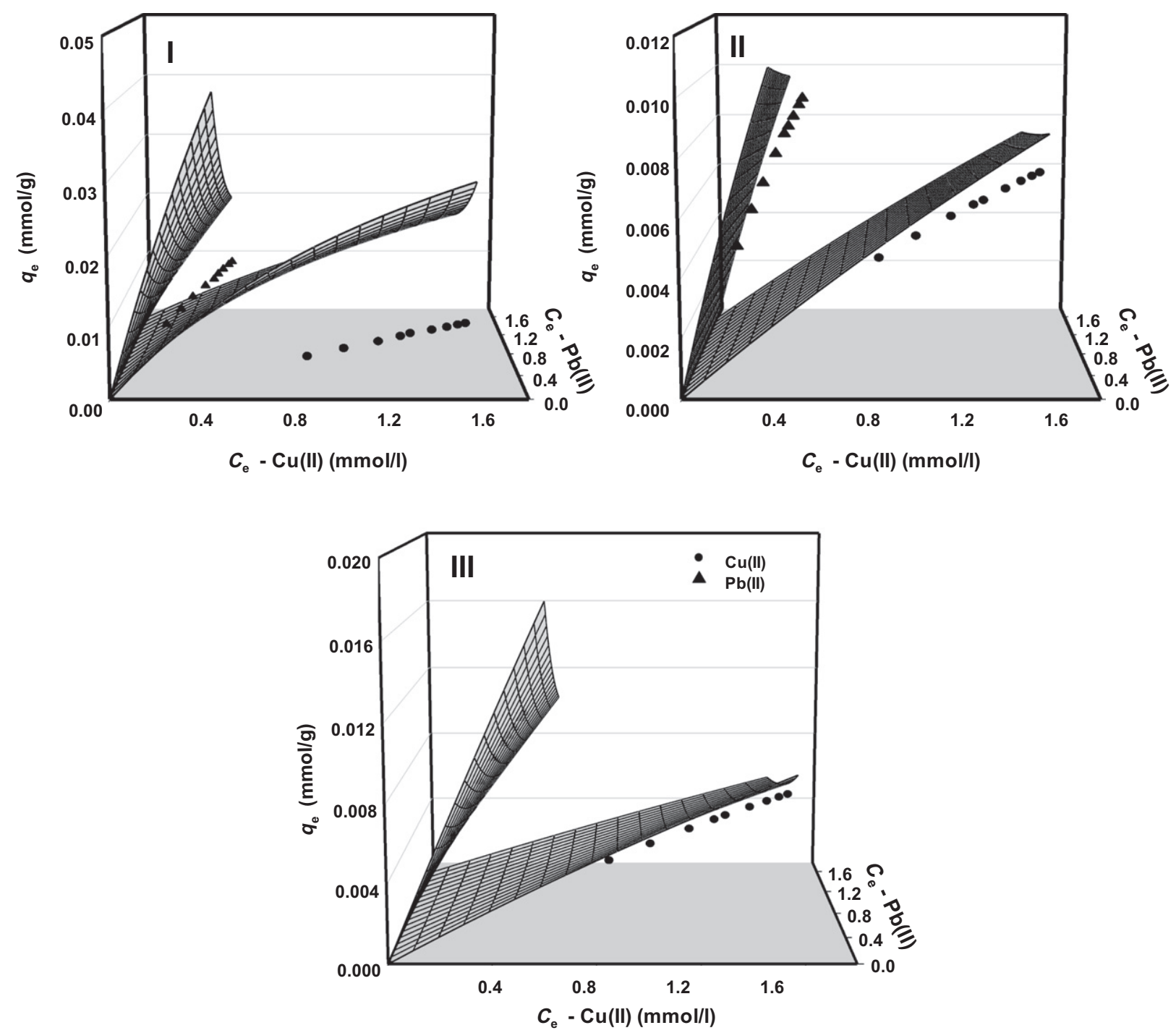

Fig. 4. Comparison of the fitted models between original extended-Langmuir ( $\mathrm{I}$ and II) and selectivity extended-Langmuir (III) against biosorption data of $\mathrm{Cu}^{2+}$ and $\mathrm{Pb}^{2+}$ ions in binary solution at $30^{\circ} \mathrm{C}$. 

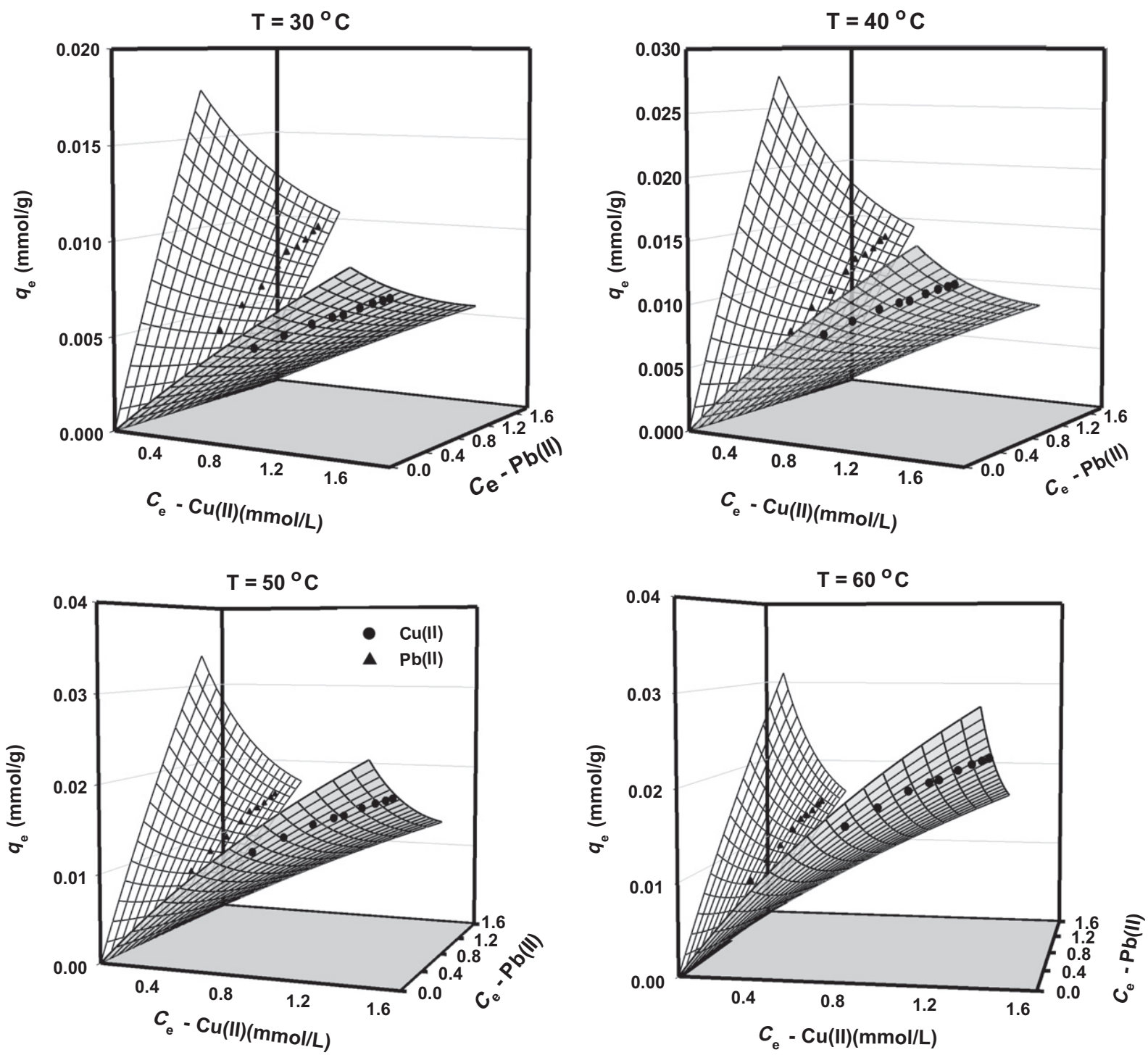

Fig. 5. The fitted model of selectivity extended-Langmuir against biosorption data of $\mathrm{Cu}^{2+}$ and $\mathrm{Pb}^{2+}$ ions in binary solution at various temperatures.

Table 4

The fitted selectivity extended-Langmuir model parameters for the biosorption of $\mathrm{Cu}^{2+}$ and $\mathrm{Pb}^{2+}$ ions from binary solution at various temperatures.

\begin{tabular}{|c|c|c|c|c|c|c|}
\hline \multirow[t]{2}{*}{$T\left({ }^{\circ} \mathrm{C}\right)$} & \multicolumn{2}{|c|}{ Fitted parameters } & \multicolumn{2}{|l|}{ Adsorptivity $^{\mathrm{a}}$} & \multirow[t]{2}{*}{$q_{\mathrm{m}-\mathrm{bin}}^{\mathrm{b}}(\mathrm{mmol} / \mathrm{g})$} & \multirow[t]{2}{*}{$R^{2}$} \\
\hline & $b_{1}$ & $b_{2}$ & $K_{\mathrm{L}, 1-\text { bin }}(1 / \mathrm{mmol})$ & $K_{\mathrm{L}, 2 \text {-bin }}(1 / \mathrm{mmol})$ & & \\
\hline \multicolumn{7}{|c|}{ Synthetic effluents } \\
\hline 30 & 0.0168 & 0.0276 & 0.1069 & 0.4698 & 0.0667 & 0.95 \\
\hline 40 & 0.0210 & 0.0309 & 0.1752 & 0.6593 & 0.0756 & 0.94 \\
\hline 50 & 0.0273 & 0.0341 & 0.2563 & 0.7426 & 0.0877 & 0.96 \\
\hline 60 & 0.0311 & 0.0367 & 0.3455 & 0.7713 & 0.0934 & 0.95 \\
\hline \multicolumn{7}{|c|}{ Real effluent } \\
\hline 30 & 0.0019 & 0.0032 & 0.1024 & 0.5523 & 0.0667 & 0.71 \\
\hline
\end{tabular}

a Calculated from Eqs. (11) and (12).

b Calculated from Eq. (10).

seen that the model can correlate experimental data satisfactorily with coefficient of determination $\left(R^{2}\right)$ ranged between 0.94 and 0.96 . The parameter values of $b_{1}$ and $b_{2}$ were determined by nonlinear regression fitting until convergence and minimum standard error of the estimate achieved. From Table 4, it can be seen that the values of $K_{\mathrm{L}, 2 \text {-bin }}$ are higher than $K_{\mathrm{L}, 1 \text {-bin }}$ at all temperatures, indicating that $\mathrm{Pb}(\mathrm{II})$ ion is more readily adsorbed onto rice straw surface than $\mathrm{Cu}(\mathrm{II})$ ion and the order of ion's affinity for the adsorption sites is consistent with the behavior in single system. At higher temperatures, the metal uptake process was more favorable due to enhanced affinity of each cation towards the biosorbent surface. Toward this end, the adsorptivities of both adsorbates in binary solution were lower than those in single system, revealing the competitive adsorption in the system. 


\subsection{Application of biosorption studies in real effluent}

The feasibility of rice straw for removing heavy metal ions was also tested using real effluent. The effluent was collected at the influent point from a wastewater treatment plant (WWTP) located in Rungkut Industrial area that contained various heavy metal ions with initial concentrations given in Table 5. Other components such as phenols, chlorides, nitrogen and sulfur compounds were also found in trace to moderate concentrations $(1-100 \mathrm{mg} / \mathrm{L})$. The $\mathrm{pH}$ of the effluent was measured by a Schott CG-825 digital $\mathrm{pH}-$ meter and found to be 4.31. Total dissolved solids (TDS) and total solids (TS) in the effluent were determined by following APHA standard methods [41] and found to be $1527 \mathrm{mg} / \mathrm{L}$ and $1912 \mathrm{mg} /$ L, respectively.

The biosorption experiments were conducted in a $250 \mathrm{~mL}$ stoppered conical flask containing $100 \mathrm{ml}$ effluent at room temperature (around $30^{\circ} \mathrm{C}$ ) and $\mathrm{pH} 6$ using biosorbent mass of $10 \mathrm{~g}$. The mixture was then shaken at $100 \mathrm{rpm}$ for $24 \mathrm{~h}$ to reach equilibrium. The characteristics of untreated and treated real effluents are listed in Table 5. It was found that the concentration of TDS in untreated effluent was unchanged after $\mathrm{pH}$ adjustment, indicating that the formation of metal hydroxide precipitates did not occur. The formation of metal hydroxide precipitates is essentially undesirable

Table 5

The characteristics of untreated and treated real effluents.

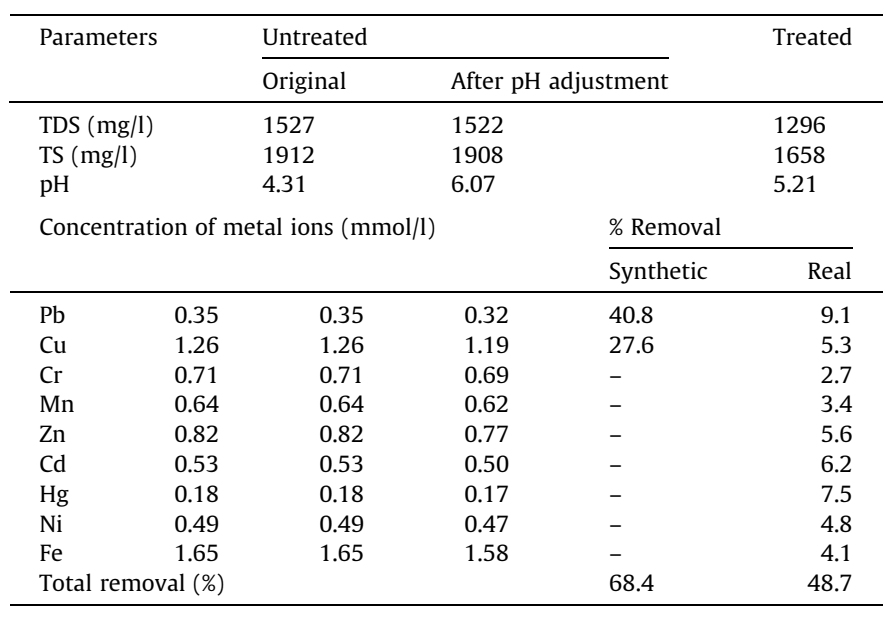

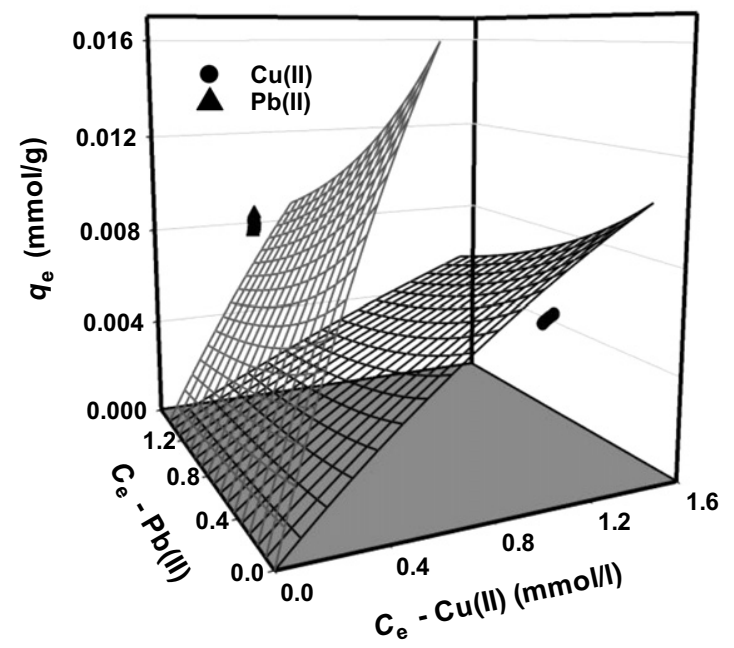

because it diminishes the concentration of free metal ions in the solution, leading to a lesser metal removal and physically change the characteristic of the effluent with respect to the increase of TSS (total suspended solids) and decreased TDS. By comparing the percentage removal of $\mathrm{Cu}$ and $\mathrm{Pb}$ ions from synthetic $(\mathrm{Cu}+\mathrm{Pb}+$ water $)$ and real effluents, the latter gave lower value for the same experimental conditions ( $68.4 \%$ vs. $48.7 \%$ ). This is likely due to a more intensive competition of solutes for the active binding sites on the solid because more solute species are presented in the adsorption system. Lower percentage removal of copper and lead ions from real effluent also attributed to the reduced affinity of both adsorbates toward the biosorbent surface. The adsorptivity of copper $\left(K_{\mathrm{L}, 1}\right)$ and lead $\left(K_{\mathrm{L}, 2}\right)$ metal ions in the multicomponent system (i.e. real effluents) should be lower than those of single and binary sorption systems. However, it was found that the affinity of $\mathrm{Pb}(\mathrm{II})$ ions in real effluent (see Table 4) was higher than that of binary effluent $(\mathrm{Cu}+\mathrm{Pb}+$ water), which verifies that the proposed model failed to describe experimental data from theoretical viewpoint. The inadequacy of the proposed model was also seen in Fig. 6, associated with a fairly poor value of the coefficient of determination $\left(R^{2}=0.71\right)$ of the fitted model against experimental results. Taking into account all of these, it can be concluded that the proposed selectivity extended-Langmuir model cannot correlate experimental adsorption data of $\mathrm{Cu}(\mathrm{II})$ and $\mathrm{Pb}(\mathrm{II})$ ions in real effluent satisfactorily. A plausible explanation to this point is that the currently proposed model only considers the competitive adsorption between two adsorbates in the solution while in the real effluent; more than two adsorbates existing and a greater extent of the sorption competition occurred. Hence, a different mathematics model or further modification of the selectivity factor concerning $n$-components should be used in order to obtain a better correlation result.

With regard to the percentage removal, the adsorptivity of metal ions toward the solid surface can be arranged from the highest to the lowest as follows: $\mathrm{Pb}>\mathrm{Hg}>\mathrm{Cd}>\mathrm{Zn}>\mathrm{Cu}>\mathrm{Ni}>\mathrm{Fe}>\mathrm{Mn}>\mathrm{Cr}$. After biosorption, the concentration of total dissolved solids in untreated effluent declined from $1522 \mathrm{mg} / \mathrm{L}$ to $1296 \mathrm{mg} / \mathrm{L}$ because of the removal of some amounts of metal ions by rice straw. The $\mathrm{pH}$ of untreated effluent became more acidic after metal ions uptake (from 6.07 to 5.21), which may be ascribed to the release of protons into the solution from the dissociation of carboxylic acids $(\mathrm{R}-\mathrm{COOH})$ into carboxylate anions $\left(\mathrm{R}^{-} \mathrm{COO}^{-}\right)$. This phenomenon acts as a preliminary stage in the metal binding process onto rice straw.

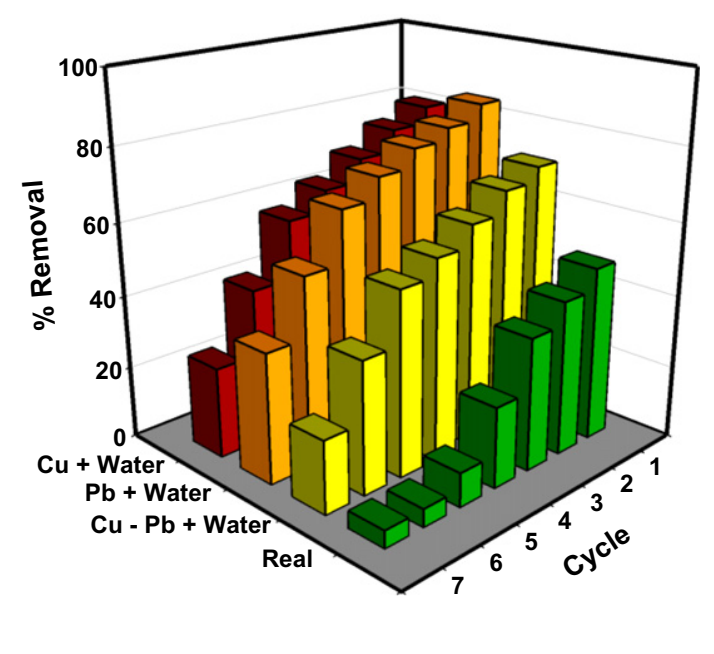

Fig. 6. The correlation of biosorption data of $\mathrm{Cu}^{2+}$ and $\mathrm{Pb}^{2+}$ ions from real effluent by selectivity extended-Langmuir model (left-hand side) and stability tests of spent biosorbent (right-hand side). 


\subsection{Desorption study of spent biosorbent}

Regenerability is one of desired criteria of adsorbent in order to make the sorption process more economical, particularly for industrial practice and explore the possibility for recovering metal resources from the liquid phase. The regenerability of rice straw in this work was evaluated by subjecting the spent biosorbent to seven-successive adsorption-desorption cycles. Desorption experiments were performed at room temperature by mixing $1 \mathrm{~g}$ of metal-loaded rice straw with $50 \mathrm{~mL}$ eluent solution in a series of stoppered conical flasks for $24 \mathrm{~h}$. The eluent solution used was dilute hydrochloric acid at initial concentration of $0.1 \mathrm{M}$. The effect of recycling time on the stability performance of rice straw in sequestering heavy metal ions from synthetic $(\mathrm{Cu}+$ water, $\mathrm{Pb}+$ water, and $\mathrm{Cu}+\mathrm{Pb}+$ water) and real effluents is shown in Fig. 6 .

Experimental results (Fig. 6) show that the repeated use of biosorbent in the case of synthetic wastewaters still feasible for five cycles with comparable percentage removal against the previous cycle. Meanwhile, the regenerated biosorbent can only be used three times for the effective removal of metal ions from real effluent. After third cycle, the adsorption capacity of biosorbent started to decline drastically and no further desorption at the sixth cycle. A shorter life time of regenerated biosorbent in this case may be ascribed to the difficulties in leaching some heavy metal ions that strongly bound in the solid matrices. Apart from this, all results above show the feasibility and potential application of rice straw for the treatment of metal-bearing effluents in large-scale operation.

\subsection{Biosorption thermodynamics}

In order to gain a complete understanding on the biosorption nature of $\mathrm{Cu}(\mathrm{II})$ and $\mathrm{Pb}(\mathrm{II})$ ions onto rice straw surface, thermodynamic aspects of the sorption process such as the standard enthalpy change $\left(\Delta H^{\circ}\right)$, the standard entropy change $\left(\Delta S^{\circ}\right)$, and the free energy change $\left(\Delta G^{\circ}\right)$ were studied. These thermodynamic parameters can be evaluated by considering the variation of apparent equilibrium constant or sorption distribution $\left(K_{\mathrm{D}}\right)$ with temperature. The mathematical relationship between the equilibrium sorption distribution and free energy change of adsorption can be expressed by the classical van't Hoff equation below:

$\Delta G^{\circ}=-R T \ln K_{D}$

where $\Delta G^{\circ}$ is the Gibb's free energy change $(\mathrm{kJ} / \mathrm{mol})$ that measures the spontaneity of a chemical reaction and can be expressed as

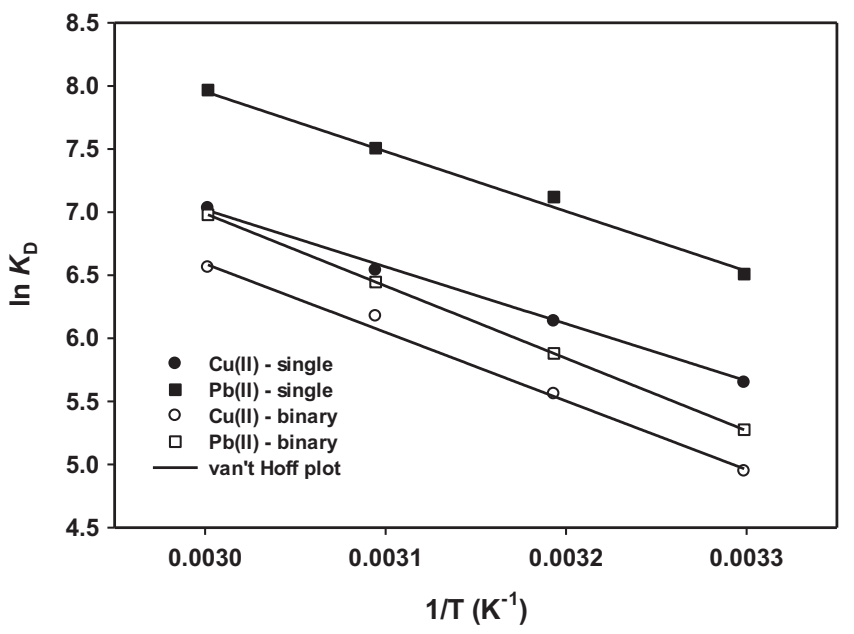

Fig. 7. The van't Hoff plot for biosorption of $\mathrm{Cu}^{2+}$ and $\mathrm{Pb}^{2+}$ ions from single and binary systems.
$\Delta G^{\circ}=\Delta H^{\circ}-T \Delta S^{\circ}, K_{\mathrm{D}}$ is the thermodynamic distribution coefficient that defined as a ratio of concentration of the solute in the adsorbed phase $(\mathrm{mmol} / \mathrm{l})$ to that in the liquid phase $(\mathrm{mmol} / \mathrm{l})$ at equilibrium, $R$ is the universal gas constant $(8.314 \mathrm{~J} / \mathrm{mol} \mathrm{K})$, and $T$ is the operating temperature $(\mathrm{K})$. The parameter $K_{\mathrm{D}}$ can be obtained by plotting a straight line of $\ln \left(q_{\mathrm{e}} / C_{\mathrm{e}}\right)$ vs. $q_{\mathrm{e}}$ and extrapolating $q_{\mathrm{e}}$ to zero according to the Khan and Singh method [42]. The standard enthalpy change and standard entropy change of an adsorption process can be determined by substituting $\Delta G^{\circ}=\Delta H^{\circ}-T \Delta S^{\circ}$ into Eq. (15) to give the following van't Hoff equation:

$\ln K_{\mathrm{D}}=\frac{\Delta S^{0}}{R}-\frac{\Delta H^{0}}{R T}$

The values of $\Delta H^{\circ}(\mathrm{kJ} / \mathrm{mol})$ and $\Delta S^{\circ}(\mathrm{kJ} / \mathrm{mol} \mathrm{K})$ can be calculated from the slope and intercept of the linear plot of $\ln K_{\mathrm{D}}$ vs. $1 / T$, respectively. By evaluating these parameters, the nature of an adsorption process can be known whether it is endothermic $\left(\Delta H^{\circ}>0\right)$, exothermic $\left(\Delta H^{\circ}<0\right)$, spontaneous $\left(\Delta G^{\circ}<0\right)$, or nonspontaneous $\left(\Delta G^{\circ}>0\right)$.

The van't Hoff plots for the biosorption of copper and lead ions onto rice straw in single component system are depicted in Fig. 7 while the corresponding thermodynamic parameters are tabulated in Table 6. From Table 6, it can be known that the biosorption of $\mathrm{Cu}^{2+}$ and $\mathrm{Pb}^{2+}$ ions by rice straw are spontaneous and endothermic in nature with respect to the negative values of $\Delta G^{\circ}$ and positive values of $\Delta H^{\circ}$. Increasing temperature led to a more negative value of $\Delta G^{\circ}$, indicating that higher temperatures energetically favor the feasibility and spontaneity of the biosorption process. This may be attributed to the faster mobility of solute molecules in the solution at elevated temperatures that enhanced their adsorptivity toward the biomass surface. By comparing the magnitude of $\Delta G^{\circ}$ values for the biosorption of copper and lead ions at the same temperature, it can be known that the biosorption of the latter species was more favorable than the former, which is consistent with the adsorption isotherm results. The endothermic behavior of the removal of copper and lead ions by rice straw revealed that an energy input (heat) is required for conducting the process and the rise in temperature increased the removal effectiveness and maximum sorption capacity of the solute. In addition, the magnitude of $\Delta H^{\circ}$ may also give an idea about the type of sorption process whether it is physisorption (i.e. $2.1-20.9 \mathrm{~kJ} / \mathrm{mol}$ ) or chemisorption (i.e. 80 $200 \mathrm{~kJ} / \mathrm{mol}$ ). As seen in Table 6, the values of $\Delta H^{\circ}$ for the biosorption of copper and lead ions using rice straw were $37.64 \mathrm{~kJ} / \mathrm{mol}$ and $39.41 \mathrm{~kJ} / \mathrm{mol}$, respectively. These values do not fall into a range of pure physical or chemical adsorption process, which suggests a combination of physisorption and chemisorption where the latter serves as the controlling mechanism. The positive values of $\Delta S^{\circ}$ were observed for copper-rice straw and lead-rice straw systems, which reflected high preference of metal cations towards the adsorption sites and a random state at the solid/solution interface with some structural changes in the adsorbate and biosorbent. Some explanations to this point were (1) the system gain more translational entropy from the displacement of adsorbed water molecules by metal cations; (2) the release of hydration waters during the transition of metallic species; (3) higher mobility of the adsorbate molecules at elevated temperatures; and (4) the distribution of translational and rotational energies during the selforientation of adsorbate species in the adsorbed state. All these phenomena might be responsible, thus allowing for the prevalence of randomness in the system. For comparison purpose, the thermodynamic behavior of the biosorption of copper and lead ions using various kinds of biomass (besides rice straw) was given in Table 6 [34,43-45].

The thermodynamic behavior of biosorption of copper and lead ions from binary solution can be determined by the same approach as of single component system [46]. It was found that the 
Table 6

Thermodynamic parameters for the biosorption of $\mathrm{Cu}^{2+}$ and $\mathrm{Pb}^{2+}$ ions by various biomass.

\begin{tabular}{|c|c|c|c|c|c|c|}
\hline Biomass & Ion & $T(\mathrm{~K})$ & $\Delta G^{\circ}(\mathrm{kJ} / \mathrm{mol})$ & $\Delta H^{\circ}(\mathrm{kJ} / \mathrm{mol})$ & $\Delta S^{\circ}(\mathrm{J} / \mathrm{mol} \mathrm{K})$ & Reference \\
\hline Rice straw & $\mathrm{Pb}^{2+}$ & $\begin{array}{l}303.15 \\
313.15 \\
323.15 \\
333.15 \\
303.15 \\
313.15 \\
323.15 \\
333.15\end{array}$ & $\begin{array}{l}-14.29 \\
-16.00 \\
-17.71 \\
-19.43 \\
-16.48 \\
-18.33 \\
-20.17 \\
-22.01\end{array}$ & 37.64 & 184.37 & This study \\
\hline Ulva lactuca & $\mathrm{Pb}^{2+}$ & $\begin{array}{l}293.15 \\
303.15 \\
313.15 \\
323.15\end{array}$ & $\begin{array}{l}-16.7 \\
-16.4 \\
-15.7 \\
-15.4\end{array}$ & -30.2 & -45.8 & {$[34]$} \\
\hline Tannin resin & $\mathrm{Pb}^{2+}$ & $\begin{array}{l}296 \\
306 \\
326 \\
346 \\
366\end{array}$ & $\begin{array}{r}-5.43 \\
-6.63 \\
-9.17 \\
-11.54 \\
-14.42\end{array}$ & 31.84 & 127.02 & {$[43]$} \\
\hline Rubber leaf powder & $\mathrm{Cu}^{2+}$ & $\begin{array}{l}300 \\
310 \\
320\end{array}$ & $\begin{array}{l}-3.38 \\
-2.17 \\
-1.48\end{array}$ & -31.96 & -95.94 & {$[44]$} \\
\hline Grafted chitosan bead & $\mathrm{Cu}^{2+}$ & $\begin{array}{l}303 \\
313 \\
323\end{array}$ & $\begin{array}{l}-14.04 \\
-14.19 \\
-14.23\end{array}$ & 11.15 & 12 & {$[45]$} \\
\hline
\end{tabular}

spontaneity of the sorption process for both heavy metals from binary solution at all temperatures was diminished likely due to the competitive adsorption occurring between the ionic species in the liquid phase. The $\Delta G^{\circ}$ values for biosorption of $\mathrm{Cu}^{2+}$ and $\mathrm{Pb}^{2+}$ ions were ranged from $-12.51 \mathrm{~kJ} / \mathrm{mol}$ to $-16.32 \mathrm{~kJ} / \mathrm{mol}$ and $-13.27 \mathrm{~kJ} / \mathrm{mol}$ to $-19.31 \mathrm{~kJ} / \mathrm{mol}$, respectively. Conversely, the values of entropy change for the removal of copper and lead ions from binary solution were higher that those of single metal removal (i.e. 190.52 J/mol K for $\mathrm{Cu}^{2+}$ and $201.20 \mathrm{~J} / \mathrm{mol} \mathrm{K}$ for $\mathrm{Pb}^{2+}$ ), reflecting a more irregular state at the solid/solution interface which might be associated with the presence of competing ion so the vacant sites on the solid surface were occupied by both components. The biosorption of $\mathrm{Cu}^{2+}$ and $\mathrm{Pb}^{2+}$ ions from their mixture was endothermic with enthalpy changes of $45.24 \mathrm{~kJ} / \mathrm{mol}$ and $47.72 \mathrm{~kJ} / \mathrm{mol}$, respectively. Higher values of $\Delta H^{\circ}$ mean that more energy is required for the metal cations to be adsorbed onto biosorbent surface as a result of competitive biosorption in the system.

\section{Conclusions}

The utilisation and evaluation of rice straw for the removal of copper and lead ions from single and binary solutions have been demonstrated in this work. Some crucial implications of this study are listed below:

- The proposed selectivity extended-Langmuir model with two fitted parameters $\left(b_{1}\right.$ and $b_{2}$ ) satisfactorily correlating biosorption equilibrium data of $\mathrm{Cu}(\mathrm{II})-\mathrm{Pb}$ (II) mixture at all temperatures compared to the classical extended-Langmuir model.

- The biosorption performance of rice straw for sequestering heavy metals from real effluent was fairly good with percentage removal of $48.7 \%$.

- The utilisation of rice straw as a natural sorbent for heavy metal ions show potential application for scale-up purpose due to its abundance in nature, low cost, and reusability.

- Thermodynamically, the biosorption of copper and lead metal ions by rice straw from single and binary solutions was spontaneous $\left(\Delta G^{\circ}<0\right)$ and endothermic $\left(\Delta H^{\circ}>0\right)$ with high preference of metal cations towards the biomass surface $\left(\Delta S^{\circ}>0\right)$.

\section{Acknowledgments}

This research was supported by the International Foundation for Science, Stockholm, Sweden, through a Grant to Felycia Edi Soetaredjo.

\section{References}

[1] K.P. Singh, D. Mohan, S. Sinha, R. Dalwani, Impact assessment of treated/ untreated wastewater toxicants discharged by sewage treatment plants on health, agricultural, and environmental quality in the wastewater disposal area, Chemosphere 55 (2004) 227-255.

[2] K. Cheyns, S. Peeters, D. Delcourt, E. Smolders, Lead phytotoxicity in soils and nutrient solutions is related to lead induced phosphorus deficiency, Environ. Pollut. 164 (2012) 242-247.

[3] L. Santorufo, C.A.M. Van Gestel, G. Maisto, Ecotoxicological assessment of metal-polluted urban soils using bioassays with three soil invertebrates, Chemosphere 88 (2012) 418-425.

[4] A. Singh, S.M. Prasad, Reduction of heavy metal load in food chain: technology assessment, Rev. Environ. Sci. Biotechnol. 10 (2011) 199-214.

[5] Y. Yi, Z. Yang, S. Zhang, Ecological risk assessment of heavy metals in sediment and human health risk assessment of heavy metals in fishes in the middle and lower reaches of the Yangtze River basin, Environ. Pollut. 159 (2011) 25752585

[6] M.H. Yu, Environmental Toxicology-Biological and Health Effects of Pollutants, second ed., CRC Press, Boca Raton, Florida, 2005.

[7] G. Chen, Electrochemical technologies in wastewater treatment, Sep. Purif. Technol. 38 (2004) 11-41.

[8] T. Kikuchi, S. Tanaka, Biological removal and recovery of toxic heavy metals in water environment, Crit. Rev. Env. Sci. Technol. 42 (2012) 1007-1057.

[9] H. Bessbousse, T. Rhlalou, J.F. Verchere, L. Lebrun, Removal of heavy metal ions from aqueous solutions by filtration with a novel complexing membrane containing poly(ethyleneimine) in a poly(vinyl alcohol) matrix, J. Membr. Sci. 307 (2008) 249-259.

[10] S.A. Abo-El-Enein, M.A. Eissa, A.A. Diafullah, M.A. Rizk, F.M. Mohamed, Utilization of a low cost agro-residue for production of coagulant aids and their applications, J. Hazard. Mater. 186 (2011) 1200-1205.

[11] L. Charerntanyarak, Heavy metals removal by chemical coagulation and precipitation, Water Sci. Technol. 39 (1999) 135-138.

[12] S. Malamis, E. Katsou, K. Takopoulos, P. Demetriou, M. Loizidou, Assessment of metal removal, biomass activity and RO concentrate treatment in an MBR-RO system, J. Hazard. Mater. 209-210 (2012) 1-8.

[13] A. Stojanovic, B.K. Keppler, Ionic liquids as extracting agents for heavy metals, Sep. Sci. Technol. 47 (2012) 189-203.

[14] S.A. Abo-Farha, A.Y. Abdel-Aal, I.A. Ashour, S.E. Garamon, Removal of some heavy metal cations by synthetic resin purolite C100, J. Hazard. Mater. 169 (2009) 190-194 
[15] N. Das, R. Vimala, P. Karthika, Biosorption of heavy metals - an overview, Indian J. Biotechnol. 7 (2008) 159-169.

[16] A. Demirbas, Heavy metal adsorption onto agro-based waste materials: a review, J. Hazard. Mater. 157 (2008) 220-229.

[17] F. Widodo, S. Wahyono, Kecernaan bahan kering, kecernaan bahan organik, produksi VFA dan $\mathrm{NH}_{3}$ pakan komplit dengan level jerami padi berbeda secara in vitro, Indonesian J. Food Technol. 1 (2012) 1-15.

[18] H. Gao, Y. Liu, G. Zeng, W. Xu, T. Li, W. Xia, Characterization of $\mathrm{Cr}(\mathrm{VI})$ removal from aqueous solutions by a surplus agricultural waste-rice straw, J. Hazard. Mater. 150 (2008) 446-452.

[19] C.G. Rocha, D.A.M. Zaia, R.V.d.S. Alfaya, A.A.d.S. Alfaya, Use of rice straw as biosorbent for removal of $\mathrm{Cu}(\mathrm{II}), \mathrm{Zn}(\mathrm{II}), \mathrm{Cd}(\mathrm{II})$ and $\mathrm{Hg}(\mathrm{II})$ ions in industrial effluents, J. Hazard. Mater. 166 (2009) 383-388.

[20] H. Muhamad, H. Doan, A. Lohi, Batch and continuous fixed-bed column biosorption of $\mathrm{Cd}^{2+}$ and $\mathrm{Cu}^{2+}$, Chem. Eng. J. 158 (2010) 369-377.

[21] Y. Ding, D. Jing, H. Gong, L. Zhou, X. Yang, Biosorption of aquatic cadmium(II) by unmodified rice straw, Bioresour. Technol. 114 (2012) 20-25.

[22] P.C.C. Faria, J.J.M. Orfao, M.F.R. Pereira, Adsorption of anionic and cationic dyes on activated carbons with different surface chemistries, Water Res. 38 (2004) 2043-2052.

[23] J.S. Han, J.S. Rowell, Chemical composition of fibers, in: R.M. Rowell, R.A. Young, J.K. Rowell (Eds.), Paper and Composites from Agro-Based Resources, CRC Press, New York, 1997, pp. 83-134.

[24] R.H. Crist, J. Robert Martin, D. Carr, J.R. Watson, H.J. Clarke, D.R. Crist Interaction of metals and protons with Algae. 4. Ion exchange vs adsorption models and a reassessment of scatchard Plots; ion-exchange rates and equilibria compared with calcium alginate, Environ. Sci. Technol. 28 (1994) 1859-1866.

[25] S. Schiewer, B. Volesky, Modeling multi-metal ion exchange in biosorption, Environ. Sci. Technol. 30 (1996) 2921-2927.

[26] S.K. Papageorgiou, E.P. Kouvelos, E.P. Favvas, A.A. Sapalidis, G.E. Romanos, F.K. Katsaros, Metal-carboxylate interactions in metal-alginate complexes studied with FTIR spectroscopy, Carbohydr. Res. 345 (2010) 469-473.

[27] I. Langmuir, The adsorption of gases on plane surfaces of glass, mica and platinum, J. Am. Chem. Soc. 40 (1918) 1361-1403.

[28] T.W. Weber, R.K. Chakravorti, Pore and solid diffusion models for fixed-bed adsorbers, AIChE J. 20 (1974) 228-238.

[29] H.M.F. Freundlich, Over the adsorption in solution, J. Phys. Chem. 57 (1906) 385-470.

[30] D.D. Do, Adsorption Analysis: Equilibria and Kinetics, first ed., Imperial College Press, London, 1998.
[31] R.D. Shannon, Revised effective ionic radii and systematic studies of interatomic distances in halides and chalcogenides, Acta Crystallogr. A 32 (1976) 751-767.

[32] E. Pehlivan, T. Altun, S. Parlayici, Utilization of barley straws as biosorbents for $\mathrm{Cu}^{2+}$ and $\mathrm{Pb}^{2+}$ ions, J. Hazard. Mater. 164 (2009) 982-986.

[33] W.M. Ibrahim, Biosorption of heavy metal ions from aqueous solution by red macroalgae, J. Hazard. Mater. 192 (2011) 1827-1835.

[34] A. Sari, M. Tuzen, Biosorption of $\mathrm{Pb}(\mathrm{II})$ and $\mathrm{Cd}(\mathrm{II})$ from aqueous solution using green alga (Ulva lactuca) biomass, J. Hazard. Mater. 152 (2008) 302-308.

[35] G. Annadurai, R.S. Juang, D.J. Lee, Adsorption of heavy metals from water using banana and orange peels, Water Sci. Technol. 47 (2003) 185-190.

[36] S. Dahiya, R.M. Tripathi, A.G. Hegde, Biosorption of lead and copper from aqueous solutions by pre-treated crab and arca shell biomass, Bioresour. Technol. 99 (2008) 179-187.

[37] G. Blazquez, M.A. Martin-Lara, E. Dionisio-Ruiz, G. Tenorio, M. Calero, Copper biosorption by pine cone shell and thermal decomposition study of the exhausted biosorbent, J. Ind. Eng. Chem. 18 (2012) 1741-1750.

[38] R. Razmovski, M. Sciban, Biosorption of $\mathrm{Cr}(\mathrm{VI})$ and $\mathrm{Cu}(\mathrm{II})$ by waste tea fungal biomass, Ecol. Eng. 34 (2008) 179-186.

[39] M.A. Hossain, H.H. Ngo, W.S. Guo, T. Setiadi, Adsorption and desorption of copper(II) ions onto garden grass, Bioresour. Technol. 121 (2012) 386395.

[40] B. Singha, S.K. Das, Biosorption of $\mathrm{Cr}(\mathrm{VI})$ ions from aqueous solutions: kinetics, equilibrium, thermodynamics and desorption studies, Colloids Surf. B 84 (2011) 221-232

[41] APHA, Standard Methods for the Examination of Water and Wastewater, 18th ed., American Public Health Association, Washington, DC, 1998.

[42] A. Khan, R. Singh, Adsorption thermodynamics of carbofuran on Sn(IV) a rsenosilicate in $\mathrm{H}^{+}, \mathrm{Na}^{+}$, and $\mathrm{Ca}^{+}$forms, Colloids Surf. 24 (1987) 33-42.

[43] M. Yurtsever, I.A. Sengil, Biosorption of $\mathrm{Pb}(\mathrm{II})$ ions by modified quebracho tannin resin, J. Hazard. Mater. 163 (2009) 58-64.

[44] W.S.W. Ngah, M.A.K.M. Hanafiah, Adsorption of copper on rubber (Hevea brasiliensis) leaf powder: kinetic, equilibrium, and thermodynamic studies, Biochem. Eng. J. 39 (2008) 521-530.

[45] M.R. Gandhi, G.N. Kousalya, N. Viswanathan, S. Meenakshi, Sorption behavior of copper on chemically modified chitosan beads from aqueous solution, Carbohydr. Polym. 83 (2011) 1082-1087.

[46] G. Uslu, M. Tanyol, Equilibrium and thermodynamic parameters of single and binary mixture biosorption of lead(II) and copper(II) ions onto Pseudomonas putida: Effect of temperature, J. Hazard. Mater. 135 (2006) 87-93. 